\title{
Medically resistant pediatric insular-opercular/perisylvian epilepsy. Part 2: outcome following resective surgery
}

\author{
*Alexander G. Weil, MD, FRCSC, ${ }^{2}$ Ngoc Minh D. Le, MD, ${ }^{1}$ Prasanna Jayakar, MD, ${ }^{1}$ \\ Trevor Resnick, MD, Ian Miller, MD, ${ }^{1}$ Aria Fallah, MD, MSc, FRCSC, ${ }^{2}$ Michael Duchowny, MD, ${ }^{1}$ and \\ Sanjiv Bhatia, MD²
}

Departments of ${ }^{1}$ Pediatric Neurology and ${ }^{2}$ Pediatric Neurosurgery, Miami (Nicklaus) Children's Hospital, Miami, Florida

\begin{abstract}
OBJECTIVE Seizure onset in the insular cortex as a cause of refractory epilepsy is underrepresented in the pediatric population, possibly due to difficulties localizing seizure onset in deep anatomical structures and limited surgical access to the insula, a complex anatomical structure with a rich overlying vascular network. Insular seizure semiology may mimic frontal, temporal, or parietal lobe semiology, resulting in false localization, incomplete resection, and poor outcome.

METHODS The authors retrospectively reviewed the records of all pediatric patients who underwent insular cortical resections for intractable epilepsy at Miami Children's Hospital from 2009 to 2015. Presurgical evaluation included video electroencephalography monitoring and anatomical/functional neuroimaging. All patients underwent excisional procedures utilizing intraoperative electrocorticography or extraoperative subdural/depth electrode recording.
\end{abstract}

RESULTS Thirteen children (age range 6 months-16 years) with intractable focal epilepsy underwent insular-opercular resection. Seven children described symptoms that were suggestive of insular seizure origin. Discharges on scalp EEG revealed wide fields. Four patients were MRI negative (i.e., there were no insular or brain abnormalities on MRI), 4 demonstrated insular signal abnormalities, and 5 had extrainsular abnormalities. Ten patients had insular involvement on PET/SPECT. All patients underwent invasive investigation with insular sampling; in 2 patients resection was based on intraoperative electrocorticography, whereas 11 underwent surgery after invasive EEG monitoring with extraoperative monitoring. Four patients required an extended insular resection after a failed initial surgery. Postoperatively, 2 patients had transient hemiplegia. No patients had new permanent neurological deficits. At the most recent follow-up (mean 43.8 months), $9(69 \%)$ children were seizure free and 1 had greater than $90 \%$ seizure reduction.

CONCLUSIONS Primary insular seizure origin should be considered in children with treatment-resistant focal seizures that are believed to arise within the perisylvian region based on semiology, widespread electrical field on scalp EEG, or insular abnormality on anatomical/functional neuroimaging. There is a reasonable chance of seizure freedom in this group of patients, and the surgical risks are low.

http://thejns.org/doi/abs/10.3171/2016.4.PEDS15618

KEY WORDS refractory epilepsy; insula; opercula; perisylvian; epilepsy surgery; insular epilepsy; pediatric; seizure

$\mathrm{R}$ ECENTLY, stereo-electroencephalography (EEG) $)^{28}$ and depth electrode recordings in patients with refractory epilepsy with perisylvian semiology have shown that the insular cortex is primarily involved in seizure generation and propagation. ${ }^{1,6,7,10,29,30}$ Epilepsy surgery failure rates range from $12 \%$ to $50 \%$; failure to consider the primary role of the insula in epileptogenesis is now regarded as an important cause of surgical failure. ${ }^{17,26,27}$ Seizures arising from the insular cortex are especially problematic as their semiology and features on

ABBREVIATIONS AED = antiepileptic drug; ECOG = electrocorticography; EEG = electroencephalography; FCD = focal cortical dysplasia; $\mathrm{MCA}=$ middle cerebral artery; TSC = tuberous sclerosis complex; TTE = time-to-event.

SUBMITTED November 13, 2015. ACCEPTED April 18, 2016.

INCLUDE WHEN CITING Published online July 29, 2016; DOI: 10.3171/2016.4.PEDS15618.

* Drs. Weil and Le contributed equally to this work. 
EEG often mimic frontal, temporal, and/or parietal lobe patterns. ${ }^{12,13,26,27}$

Progress in understanding the physiological relationships and vascular anatomy of the insula together with the introduction of more sophisticated stereotactic and microsurgical techniques have improved the outcomes of insular epilepsy surgery. ${ }^{23}$ Recent reports, mostly in adult patients, have shown that insular-opercular invasive investigation and resection are both feasible and effective. 1,13,21,29 However, surgical experience with insular epilepsy surgery, particularly in children, remains limited due to the limitations of noninvasive monitoring (particularly scalp EEG), challenging access to the insula for depth electrode recording and the significant risk of surgical morbidity in insular-opercular resection. ${ }^{7,13,14}$ Very few studies have described surgery of the insular/perisylvian region in children. ${ }^{8}$

To further describe insular-opercular seizures in early life and the role of surgery, we herein report, to our knowledge, the largest single-center cohort of pediatric patients undergoing resective surgery of the insular-opercular/ perisylvian cortex for refractory epilepsy.

\section{Methods}

\section{Study Design and Preoperative Evaluation}

We reviewed an electronic database that was prospectively maintained by an experienced senior epileptologist at Miami Children's Hospital. This database is updated in real time during the epilepsy surgery conference or immediately following surgery and at follow-up visits. We queried the database for patients with insular epilepsy and reviewed medical records of consecutive patients undergoing resection involving the insula for management of medically refractory epilepsy at Miami Children's Hospital between September 2009 and April 2015. All surgical insular epilepsy cases during the study period were included. We review all of our surgical failures and hence do not think that any cases with suspected insular epilepsy were missed during the study period. All patients had intractable focal epilepsy and underwent comprehensive noninvasive presurgical evaluation, which always included detailed history and physical examination, long-term video-EEG monitoring, 3-T MRI, and functional imaging (PET and/or SPECT), as previously reported. $.^{15,16,23} \mathrm{~Pa}-$ tients also underwent functional MRI for localization of relevant eloquent areas.

Image coregistration of multiple modalities was routinely performed to more precisely define the epileptogenic region and its relationship to eloquent cortex. Data review at a multidisciplinary epilepsy surgery conference attended by pediatric epileptologists, neurosurgeons, neuroradiologists, neuropsychologists, and neurophysiologists led to a comprehensive surgical treatment plan. Invasive investigation with insular sampling for epileptogenic and functional mapping was performed in all cases. Most patients underwent a 2-stage resection with extraoperative mapping. In 2 patients with well-defined lesional focal epilepsy with congruent noninvasive data, single-stage electrocorticography (ECoG)-guided resection with insular and hemispheric sampling was performed prior to resection. The topography for the placement of insular and perisylvian electrodes was determined from multimodality noninvasive testing results. The rationale for exposing the patients to the risks associated with splitting the sylvian fissure and investigating the insula was justified based on both a high degree of suspicion for insular seizures in these patients and the concern that unrecognized insular seizures are a significant cause of epilepsy surgery failure. Clinical suspicion was based on clinical semiology, lesion visualized on MRI, video-EEG/source localization, and PET or SPECT imaging demonstrating involvement of the insula within the epileptogenic zone. The surgeons were also confident that there would be limited morbidity associated with sylvian fissure dissection and wide exposure of the insular cortex.

\section{Resective Surgery Technique}

Following extraoperative invasive monitoring for epileptogenic zone and functional mapping, including placement of insular depth and hemispheric grid/strip electrodes, patients underwent second-stage corticectomy (Fig. 1). All patients underwent a wide fronto-temporo-parietal craniotomy. Care was taken to drill the lesser wing of the sphenoid to facilitate wide anterior microsurgical access to the insula through the limen insulae. The dura was opened widely and reflected forward. The sylvian fissure was first opened widely in its operculo-insular segment to avoid loss of CSF. This facilitated wide microsurgical dissection to expose the vertical limbs of the insula. An attempt was then made to expose the sylvian fissure along its entire length. A wide initial exposure was preferred as it facilitates placement of depth electrodes and subsequent insular resection. This also avoids the difficulties that may be encountered when obtaining a wider insular exposure at the time of resection. Exposure of the anterior short and posterosuperior long insular gyri was then obtained. The $\mathrm{M}_{2}$ middle cerebral artery (MCA) vessels were followed to the $\mathrm{M}_{3}$ divisions to obtain maximal exposure of the superior and inferior limiting sulcus where the branches of the MCA turn around the frontoparietal and temporal opercula.

Following the decision to resect the insula, the frontal and temporal opercula were gently retracted. The insular cortex was incised, and subpial resection of the insular cortex was performed with the aid of a No. 5 Rhoton microsurgical dissector. Great care was taken to achieve a wide subpial resection while avoiding extending into the lentiform nucleus. The insular cortex was resected subpially using 5-F suction and Rhoton microdissectors. Bleeding was controlled using bipolar cauterization and the application of Surgicel. Papaverine was instilled locally to avoid vasospasm. Injury to some sylvian long $\mathbf{M}_{2}$ perforating arteries to the insular cortex was often unavoidable, but extra caution was exercised to protect perforating lenticulostriate vessels that supply the internal capsule and centrum semiovale. The extent of insular resection was tailored by direct EEG guidance. Additional opercular, temporal, or orbitofrontal resection was also carried out as required. We prefer to apply topical papaverine at the end of the procedure to avoid spasm of the $\mathrm{M}_{3}$ vessels. 

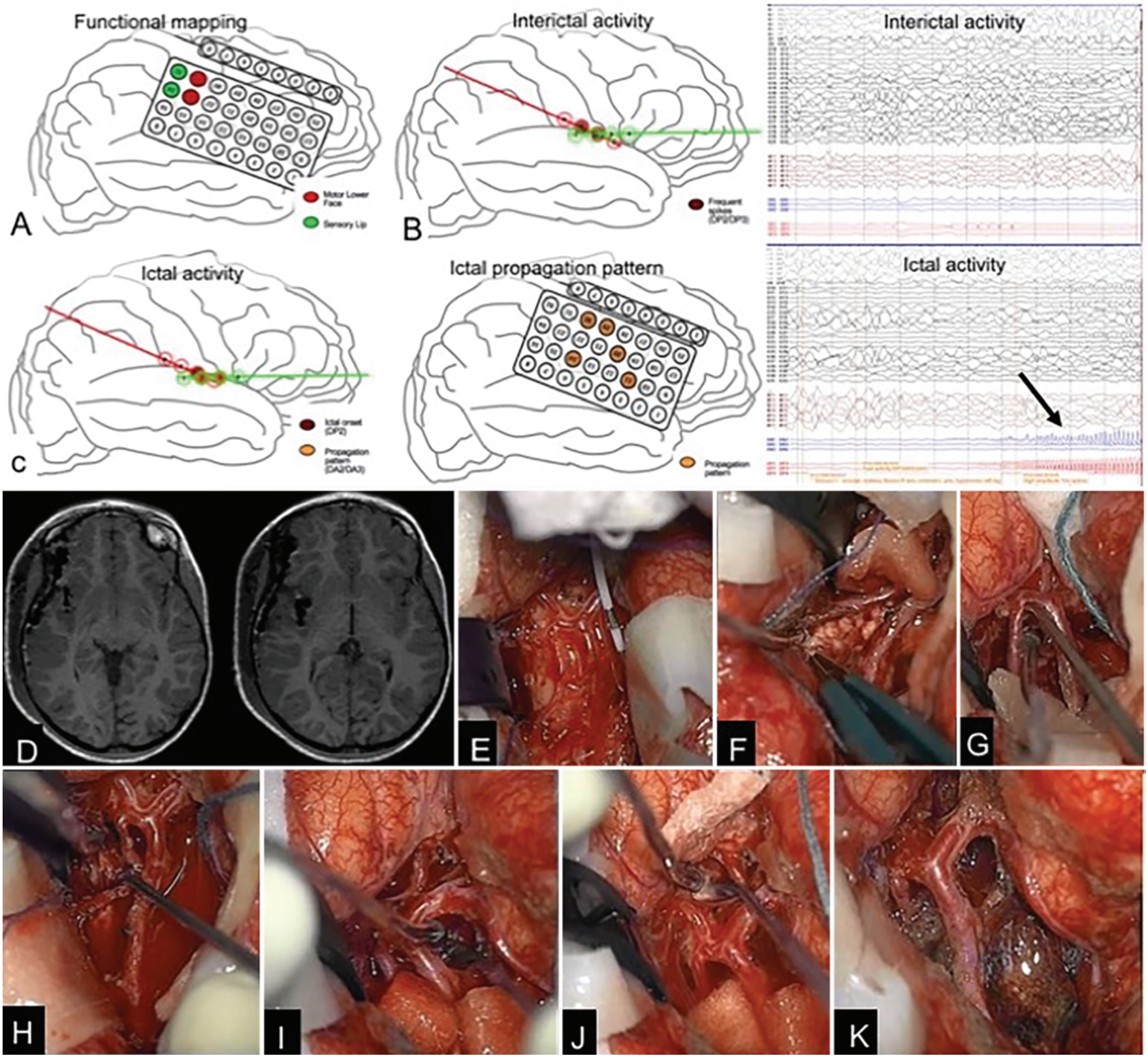

FIG. 1. Case 1. Illustrative case. Two insular electrodes were placed in this patient: a parasagittal transinsular apex depth electrode and a second electrode from a posterior approach after splitting the sylvian fissure. A: Brain schematic showing functional mapping following invasive investigation. B: Interictal activity originating from the insula as shown on schematic brain and videoEEG. C: Ictal activity and propagation within the insula as shown on schematic brain and invasive video-EEG. D: MR image obtained after implantation, showing the electrodes within the insula. E: Microsurgical resection. After splitting the superficial and deep operculoinsular sylvian cistern, insular resection is undertaken. The insular electrodes are used as guides during resec-

tion. F-K: The insular cortex is resected while working in between the $\mathrm{M}_{2}$ branches of the MCA, working posterior $(G)$, superior $(F$ and $\mathrm{H}$ ), inferior $(\mathrm{I})$, and anterior $(\mathrm{J})$ to the MCA branches, which are all well preserved following insulectomy $(\mathrm{K})$. Figure is available in color online only.

\section{Outcome Assessment and Data Collection}

Collected variables included demographic data (patient sex, duration of epilepsy, and age at time of surgery), seizure data (frequency and semiology), side of surgery, history of presumed etiology, extent of insular-opercular/ perisylvian resection based on MRI findings, and patho- logical substrate. Radiological data included assessment of MRI, EEG, SPECT, PET, and source localization whenever available.

We assessed seizure outcome in several ways, including Engel classification, percentage of seizure reduction, postoperative change in quantity of antiepileptic drug (AED) 
use, and a time-to-event (TTE) measure (i.e., time to first seizure after surgery). ${ }^{2,4}$ For the TTE Kaplan-Meier analysis, an event was defined as any seizure other than those in the 1st postoperative week and auras. We also excluded reactive seizures and those attributable to poor AED compliance or weaning of AEDs. TTE analysis has several advantages over a yes/no seizure recurrence approach. 1) The analysis takes into account the changing seizure status and variability in duration of follow-up, thereby increasing our sample (patients with short follow-up can be included in this model). 2) The approach places a positive value on delay in seizure recurrence. 3) Using Cox regression, it allows for examining the influence of various patient-level covariates on seizure outcome. 4) It is statistically more powerful than the yes/no approach. However, the main disadvantage of this approach is that it will fail to account for the "running down phenomenon" (gradual decline of seizures over several months or years until seizure freedom is achieved following surgery). ${ }^{2}$ Outcome data also included presence and type of complications.

\section{Results \\ Clinical Data}

We identified 13 children who underwent insular resections (5 males and 8 females); the mean age at seizure onset was 2.8 years, and the mean age at surgery was 8 years (range 6 months -16 years) (Table 1). The mean time between age at seizure onset and insular resection was 8.2 years (range $0.5-6.5$ years). Three patients underwent resective surgery prior to insular-opercular resection; 1 patient underwent parietal tuber resection and 2 underwent anterior temporal lobectomies. Patients were receiving a mean of 2.1 antiseizure medications (range 1-4) prior to the initial insular-opercular resection.

Seizure semiology for each patient is listed in Table 2. Seven patients exhibited seizures with early seizure semiology that suggested primary insular and/or opercular involvement, including characteristic pharyngeal or laryngeal discomfort/aura in 3; neurovegetative symptoms including tachycardia, pupillary mydriasis, and facial flushing in 1; emotional auras in 2; oropharyngeal responses such as hypersalivation and gagging and guttural sounds in 3 (suggesting opercular origin); and cephalic symptoms ("feeling spiders in her head") in $1 .{ }^{13}$ Five children did not experience subjective early symptoms, but most were too young (all $<8$ years old) to verbally express somatosensory symptoms.

\section{EEG Data}

Scalp EEG recordings for all patients evidenced a lateralized widespread electrographic field that included the perisylvian opercular region (frontal, temporal, and parietal electrodes) (Table 3).

\section{Neuroimaging Data}

MRI of the brain was performed in all patients (Table 3). The MRI study was nonlesional (i.e., it did not reveal lesions) in 4 patients. In 4 patients, MRI revealed lesions outside the insula, including 2 patients with FLAIR hyperintensities in the anterior temporal lobe without clear in-
TABLE 1. General demographics prior to insular resection

\begin{tabular}{|c|c|c|c|c|c|}
\hline $\begin{array}{l}\text { Case } \\
\text { No. }\end{array}$ & Sex & $\begin{array}{c}\text { Age at } \\
\text { Seizure } \\
\text { Onset (yrs) }\end{array}$ & $\begin{array}{l}\text { Age at } \\
\text { Surgery } \\
\text { (yrs) }\end{array}$ & $\begin{array}{c}\text { Prior } \\
\text { Surgery }\end{array}$ & $\begin{array}{l}\text { No. of } \\
\text { Preop } \\
\text { AEDs }\end{array}$ \\
\hline 1 & $\mathrm{~F}$ & 1 & 5 & No & 2 \\
\hline 2 & $\mathrm{~F}$ & 8 & 13.5 & No & 1 \\
\hline 3 & $\mathrm{~F}$ & 3 & 7.5 & Lt ATL \& OF corticectomy & 1 \\
\hline 4 & $\mathrm{~F}$ & 0.25 & 6.5 & No & 2 \\
\hline 5 & M & 0 & 0.5 & No & 2 \\
\hline 6 & $\mathrm{~F}$ & 3 & 7.5 & No & 3 \\
\hline 7 & $M$ & 3.5 & 10 & Lt 2-phase ATL & 3 \\
\hline 8 & $\mathrm{~F}$ & 7 & 9 & No & 4 \\
\hline 9 & M & 2 & 8 & No & 2 \\
\hline 10 & M & 15.5 & 16 & No & 1 \\
\hline 11 & M & 0.25 & 2.5 & Rt parietal tuberectomy & 1 \\
\hline 12 & $\mathrm{~F}$ & 5 & 11 & No & 4 \\
\hline 13 & $\mathrm{~F}$ & 3 & 7.6 & No & 1 \\
\hline
\end{tabular}

$\mathrm{ATL}=$ anterior temporal lobectomy; $\mathrm{OF}=$ orbitofrontal.

volvement of the insula and 2 patients with isolated frontal lobe lesions (atrophy and focal cortical dysplasia [FCD]), 1 of whom had involvement of the opercular cortex. In 5 patients, MRI demonstrated lesions involving the insula. In the 3 patients with tuberous sclerosis complex (TSC), MRI showed multiple tubers extending into the insula (1 calcified) in 2 patients and in the parietal operculum reaching the edge of posterior insula in 1. MRI in the 2 other patients showed insular abnormalities, including 1 patient with subtle nonspecific FLAIR hyperintensity in the right insula and another with perisylvian/insular atrophy.

FDG-PET scanning was performed in all but 2 patients (Table 3). PET scans were negative in 5 patients. Six scans demonstrated interictal hypometabolism that was congruent with the ictal onset zone; 4 of these 6 patients had insular hypometabolism. Ten of the 13 patients underwent ictal SPECT scanning. Although the PET scan for the patient in Case 6 did not reveal insular involvement, ictal SPECT was deemed unnecessary as brain MRI showed a definitive insular lesion. Of the 10 ictal SPECT scans, hyperperfusion involved the insula in 8 (with or without the adjacent perisylvian cortex), whereas 2 had hyperperfusion in the periinsular cortex only. ${ }^{13}$ The patient in Case 2 did not show insular involvement on MRI, PET, or SPECT, but scalp EEG recording demonstrated a widespread electrographic field (temporo-parieto-occipital) that included the operculum, and intracranial EEG recording confirmed insular seizure onset (Fig. 2).

\section{Invasive Investigation}

All medically resistant cases of suspected insular epilepsy potentially amenable to surgical resection were confirmed with invasive monitoring. Invasive investigations were performed in all 13 patients, including extraoperative recording and stimulation with perisylvian and insular sampling in 11 cases. Depth electrodes were placed in the insula with hemispheric subdural strips and grids through 
TABLE 2. Seizure semiology

\begin{tabular}{cll}
\hline Case No. & \multicolumn{1}{c}{ Early/lnitial Symptoms } & Semiology \\
\hline 1 & None & Lt $>$ rt arm tonic $\rightarrow$ rt face/hand clonic $\rightarrow$ bilat hypermotor \\
\hline 2 & Hypersalivation & Eye deviation to rt $\rightarrow$ rt arm tonic \\
\hline 3 & Dysgeusia, olfactory aura, epigastric aura (stomach "tickles") & Facial flushing \& tachycardia $\rightarrow$ bilat arms clonic \\
\hline 4 & None & Behavioral arrest $\rightarrow$ hypotonia $\rightarrow$ It arm tonic \\
\hline 5 & None & Bilat arm \& leg clonic $\rightarrow$ hypotonia $\rightarrow$ epileptic spasm \\
\hline 6 & Laryngeal aura (choking) or cephalic sensation ("spiders in head") & Bilat tonic \\
\hline 7 & NVS (pupillary mydriasis, tachycardia), psychic aura (fear), pharyn- & Rt head deviation $\rightarrow$ bilat arm tremors \\
& geal aura (tooth pain), acoustic aura, olfactory aura & \\
\hline 8 & Psychic aura (fear) & Guttural sounds $\rightarrow$ rt arm clonic $\rightarrow$ rt arm dystonia \\
\hline 9 & Hypersalivation & $\begin{array}{l}\text { Hypermotor movement of arms \& legs } \rightarrow \text { rt arm flexed } \rightarrow \text { It arm } \\
\text { extension } \rightarrow \text { It versive movement of head } \rightarrow \text { fencing position }\end{array}$ \\
\hline 10 & Pharyngeal aura (goose bumps under chin) & Lt face \& hand tonic flexion, expressive aphasia \\
\hline 11 & None & Behavioral arrest $\rightarrow$ eye blinking, versive eye movements, oral \\
& & automatisms \& bilat arm extension
\end{tabular}

NVS = neurovegetative symptoms.

an open craniotomy in all patients except 1 , in whom stereo-EEG was used. In 11 patients, a parasagittal transinsular apex depth electrode was placed through an open craniotomy following dissection of the sylvian fissure. In the 2 remaining patients, insular electrodes were placed using stereo-EEG in one and using frameless stereotaxy (frontal transopercular insular electrode) in the other. In 2 patients (Cases 4 and 13), intraoperative electrocorticography (ECoG) via depth electrodes on the insula was sufficient to map the epileptogenic zone because the com-

TABLE 3. Presurgical evaluation (Stage I) data

\begin{tabular}{|c|c|c|c|c|c|c|}
\hline $\begin{array}{l}\text { Case } \\
\text { No. }\end{array}$ & $\begin{array}{l}\text { Surface EEG } \\
\text { Interictal }\end{array}$ & $\begin{array}{l}\text { Surface EEG } \\
\text { Ictal }\end{array}$ & MRI & PET & Ictal SPECT & $\begin{array}{l}\text { Invasive Monitoring } \\
\text { Ictal Onset }\end{array}$ \\
\hline 1 & $\begin{array}{l}\mathrm{F} 4 / \mathrm{C} 4 / \mathrm{T} 4 / \mathrm{T} 6 / \mathrm{P} 6 \\
\text { spikes }\end{array}$ & $\begin{array}{l}\text { Fp2/F4/F8/T4 fast/ } \\
\text { sharp }\end{array}$ & Nonlesional & Negative & $\begin{array}{l}\text { Rt ins, frontal \& } \\
\text { temporal lobes }\end{array}$ & Rt ins \\
\hline 2 & $\begin{array}{l}\text { T3/T5/P3/01 } \\
\text { spikes/theta }\end{array}$ & $\begin{array}{r}\text { T3/T5 rhythmic } \\
\text { theta } \rightarrow \text { fast }\end{array}$ & Lt anterior temporal lobe & Negative & Rt frontal & Lt anterior temporal \& ins \\
\hline 3 & F7/T3 spikes & $\begin{array}{l}\text { F7/T3 spikes \& } \\
\text { postictal slow }\end{array}$ & Nonlesional & Negative & Lt ins \& frontal & Lt ins \& temporal pole \\
\hline 4 & F4/T4/P4 spikes & T4 fast & Multiple tubers, including ins & Negative & Rt ins \& frontal & $\begin{array}{l}\text { ECoG: rt frontal \& ins } \\
\quad \text { (interictal) }\end{array}$ \\
\hline 5 & $\begin{array}{l}\text { C4/T4 spikes, T4/ } \\
\text { T6 fast }\end{array}$ & C4/T4/T6 spikes & Nonlesional & $\begin{array}{l}\text { Rt ins (hyper- } \\
\text { metabolism) }\end{array}$ & $\begin{array}{l}\text { Rt ins, frontal, \& } \\
\text { temporal }\end{array}$ & Rt fronto-temporal \& ins \\
\hline 6 & F4/C4/T4/T8 spikes & F4 fast & Rt ins & Rt frontal & Not done & Rt ins \\
\hline 7 & F7/T3 spikes & F7/T3 spikes & Lt anterior temporal lobe & Lt ins & Lt ins \& orbitofrontal & Lt orbital frontal \& ins \\
\hline 8 & F4 \& F7/T3 spikes & Fp1/F3 theta & Nonlesional & Negative & Lt ins & Lt anterior temporal \& ins \\
\hline 9 & C4/Fp2/F8/F4 & $\begin{array}{l}\text { T6/P4/T4 rhythmic } \\
\text { slowing, alpha C4 }\end{array}$ & Rt frontal FCD & Rt frontal & Rt frontal & No seizures \\
\hline 10 & Right C4/P4 & Centroparietal & $\begin{array}{l}\text { Rt middle frontal gyrus atrophy, } \\
\text { opercular prominence }\end{array}$ & $\begin{array}{l}\text { Rt sylvian } \\
\text { fissure }\end{array}$ & Not done & Rt parietal \& ins \\
\hline 11 & $\mathrm{P} 4$ to $\mathrm{C} 4 / \mathrm{T} 4$ & $\mathrm{C} 4 / \mathrm{T} 4$ & $\begin{array}{l}\text { Multiple tubers including rt pari- } \\
\text { etal operc (posterior ins), old } \\
\text { remote parietal surgical cavity }\end{array}$ & Not done & $\begin{array}{l}\text { Rt parietal oper- } \\
\text { culum }\end{array}$ & $\begin{array}{l}\text { Rt posterior temporal \& } \\
\text { posterior ins }\end{array}$ \\
\hline 12 & F4/C4 sharp waves & $\begin{array}{l}\text { F4/Fp2/F8 w/ } \\
\text { spread to C4 }\end{array}$ & $\begin{array}{l}\text { Rt FP, opercular, temporal, } \\
\text { insular atrophy }\end{array}$ & Rt FTP \& ins & Not done & Posterior ins \\
\hline 13 & Lt FT & $\mathrm{FT}$ & $\begin{array}{l}\text { Multiple tubers including anterior } \\
\text { ins }\end{array}$ & Not done & $\begin{array}{l}\text { Lt anterior ins \& } \\
\text { orbitofrontal }\end{array}$ & $\begin{array}{l}\text { ECoG: insular tuber \& } \\
\text { perituber (interictal) }\end{array}$ \\
\hline
\end{tabular}

$\mathrm{C}=$ central; $\mathrm{F}=$ frontal; $\mathrm{FP}=$ frontoparietal; $\mathrm{Fp}=$ frontopolar; $\mathrm{FT}=$ frontotemporal; $\mathrm{FTP}=$ fronto-temporo-parietal; ins $=$ insula; $\mathrm{O}=$ occipital; $\mathrm{P}=$ parietal; $\mathrm{T}=$ temporal. 


\begin{tabular}{|c|c|c|c|c|c|}
\hline Patient & Early Sx & MRI & PET & SPECT & ictal ic-vEEG \\
\hline 1 & & & & & \\
\hline 2 & & & & & \\
\hline 3 & & & & & \\
\hline 4 & & & & & \\
\hline 5 & & & & & \\
\hline 6 & & & & & \\
\hline 7 & & & & & \\
\hline 8 & & & & & \\
\hline 9 & & & & & \\
\hline 10 & & & & & \\
\hline 11 & & & & & \\
\hline 12 & & & & & \\
\hline 13 & & & & & \\
\hline
\end{tabular}

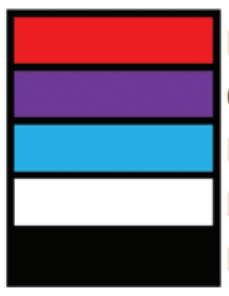

Insular +/-extra-insular

Opercular without insular

Extra-insular/opercular (frontal, temporal, parietal, or occipital)

Negative

Not done

FIG. 2. Noninvasive and invasive investigation in the 13 patients. $S x=$ seizures. ic-vEEG = intracranial video-EEG. Figure is available in color online only.

bination of MRI, PET hypometabolism, and ictal SPECT hyperperfusion was felt to be convincing evidence of insular involvement. In all but one patient (Case 9) undergoing extraoperative mapping, the insula was documented to be the region of seizure onset in addition to varying degrees of perisylvian cortex, revealing either spike-wave discharges or rhythmic fast frequencies.

\section{Surgical and Outcome Data}

Insular resection involved the left side in 5 patients and the right side in 8 patients. The resection plane always included the extrainsular cortex from the frontal, parietal, or temporal lobe (Fig. 3, Table 4). Four patients underwent a second resection of residual insular tissue, with 3 becoming seizure free (Fig. 4). Another patient (Case 1) required a third 2-stage parietal corticectomy. The final resection on MRI for each patient is shown in Fig. 3.

The mean follow-up duration was 43.8 months (range 6-60 months). Good seizure outcome was obtained in 10 (77\%) patients, including $9(69 \%)$ who had Engel Class I outcome. The mean time to seizure recurrence was 32.6 months (range 18.5-46.6 months) (Fig. 5). Five patients were weaned off at least 1 antiseizure medication, including the patient in Case 3 who was weaned off all antiseizure medications. One patient (Case 5) had a poor seizure outcome (Engel Class IV) and received an additional antiseizure medication. Another patient (Case 10) had a poor outcome related to progression of Rasmussen's encephalitis, with persistent seizures despite further medical treatment with steroids, rituximab, intravenous immunoglobulin, and CellCept (mycophenolate). Surgical data are summarized in Table 4.

There were 2 procedure-related complications. The patient in Case 5 had a postoperative MCA territory stroke following the second insulectomy causing a hemiparesis that completely resolved, and the patient in Case 3 had transient expressive aphasia and hemiparesis for 3 days following insulectomy.

Histopathological examination of the resected specimen showed FCD ( $n=9)$, Rasmussen's encephalitis ( $\mathrm{n}=$ $1)$, and TSC $(n=3)$. Postoperative/outcome data are summarized in Table 4.

\section{Discussion}

To our knowledge, our series is the largest series of pediatric patients undergoing resective surgery for refractory insular/perisylvian epilepsy. Besides generating symptoms consistent with primary insular involvement, insular seizures also mimic seizures arising in contiguous brain regions. ${ }^{13,20,21}$ Associated structures typically include the frontal, temporal, and parietal opercula, but mesial temporal and frontocentral regions are also implicated in insular seizure semiology..$^{13}$ The overlapping seizure semiology and close anatomical connection of contiguous structures 

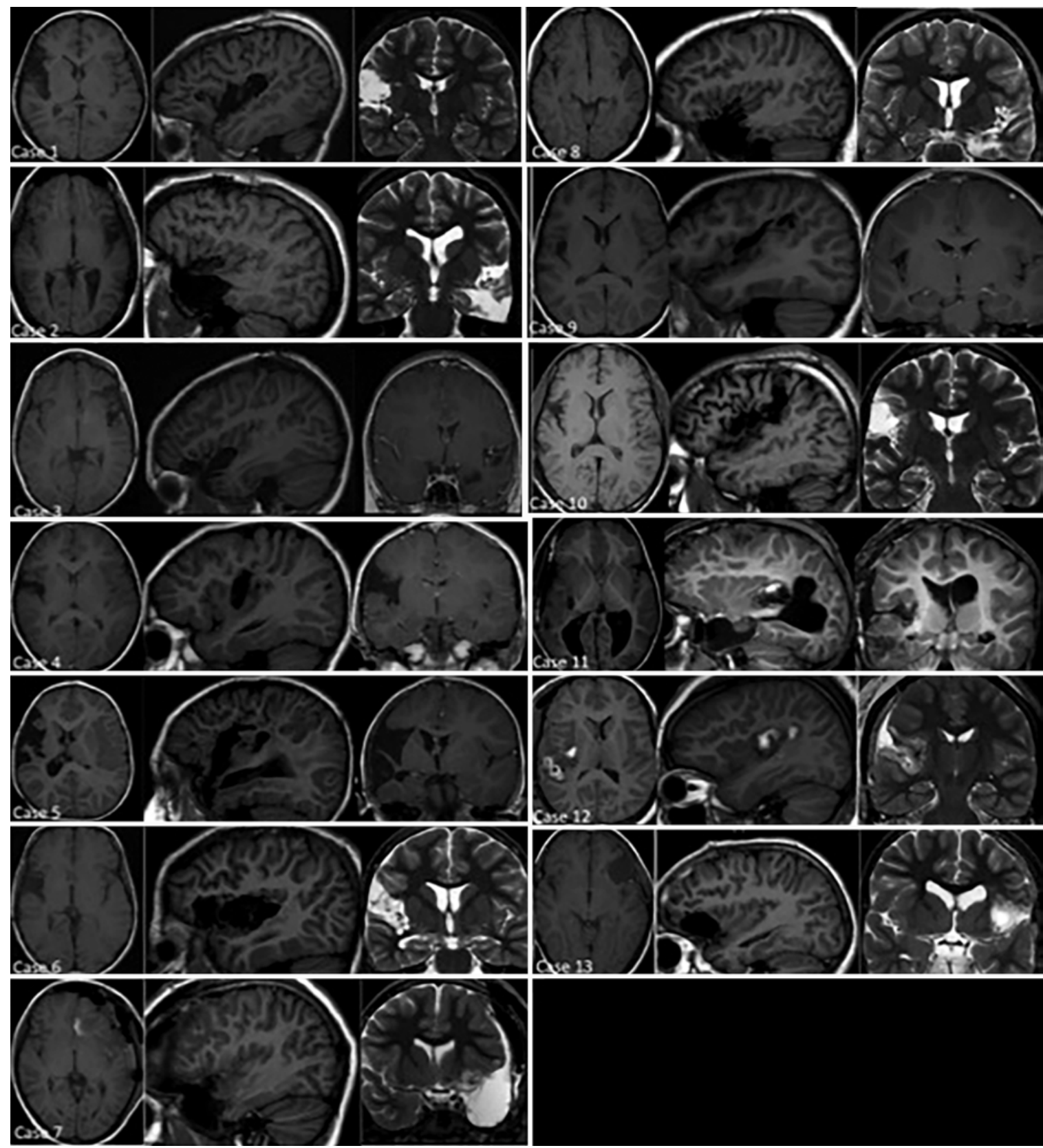

FIG. 3. Postoperative MRI showing resection in the 13 patients undergoing insular-opercular/perisylvian resection.

to the insular cortex often lead to diagnostic uncertainty and are an important source of failure in epilepsy patients undergoing frontal, temporal, or parietal lobe resections.

\section{Diagnosing Insular-Opercular Epilepsy in Children}

Since the initial description of insular epilepsy in 2004, several studies have validated typical semiology and some have suggested a somatotopy, in which viscerosensory symptoms arise from the anterior insula, somatosensory symptoms arise from the posterior insula, and sympathetic effects occur in the dominant insula. ${ }^{13,20-22}$ However, almost half of our patients did not have typical insular semiology, likely because symptoms of insular epilepsy are of- ten subjective (viscerosensory, somatosensory) and young children may not be able to express these symptoms. ${ }^{8}$ However, $54 \%$ of patients did have typical early seizure manifestations consistent with insular epilepsy, including somatosensory symptoms, pharyngeal or laryngeal aura, and neurovegetative symptoms, all consistent with other pediatric insular epilepsy series. ${ }^{8}$

All patients had electrographic fields involving more than 1 lateral cortical surface on scalp EEG. Although this pattern is not diagnostic for insular involvement, it is more consistent with a deep epileptogenic source. When combined with additional semiology and neuroimaging data, the index of suspicion for insular involvement should be 
TABLE 4. Surgical and postsurgical data and outcomes

\begin{tabular}{|c|c|c|c|c|c|c|c|c|c|c|}
\hline $\begin{array}{l}\text { Case } \\
\text { No. }\end{array}$ & $\begin{array}{l}\text { Surgery } \\
\text { Side }\end{array}$ & Insular Region & $\begin{array}{c}\text { Other Resected } \\
\text { Areas }\end{array}$ & $\begin{array}{c}\text { No. of } \\
\text { Insular } \\
\text { Resections }\end{array}$ & Pathology & $\begin{array}{l}\text { Follow-Up } \\
\text { Period } \\
\text { (mos) }\end{array}$ & $\begin{array}{l}\text { Time to } \\
\text { Event } \\
\text { (mos) }\end{array}$ & $\begin{array}{l}\text { Engel } \\
\text { Class }\end{array}$ & $\begin{array}{l}\% \text { Seizure } \\
\text { Reduction }\end{array}$ & $\begin{array}{l}\text { AED } \\
\text { Change }\end{array}$ \\
\hline 1 & Rt & $\begin{array}{l}\text { Complete (post ins } \\
\text { then complete in 2nd } \\
\text { stage) }\end{array}$ & $\begin{array}{l}\text { Frontal, parietal, \& } \\
\text { temporal operc } \\
\text { (2nd stage after } \\
\text { failed posterior ins) }\end{array}$ & 2 & FCD (Palmini Ila) & 60 & 3 & I & 90 & 0 \\
\hline 2 & $\mathrm{Lt}$ & Partial (posteroinferior) & ATL (neocortical) & 1 & FCD (Palmini Ib) & 51 & 36 & $\mathrm{Ila}$ & 99 & 0 \\
\hline 3 & $\mathrm{Lt}$ & Partial (posteroinferior) & OF \& ATL & 2 & FCD (Palmini Ib) & 56 & 56 & $\mathrm{lb}$ & $100^{*}$ & -1 \\
\hline 4 & Rt & Partial (posterosuperior) & Operc \& frontal & 1 & TSC & 46 & 46 & la & 100 & -1 \\
\hline 5 & Rt & Complete & $\begin{array}{c}\text { Frontal, parietal, \& } \\
\text { temporal operc }\end{array}$ & 2 & FCD (Palmini Ila) & 40 & 6 & IV & $<50$ & +1 \\
\hline 6 & $\mathrm{Rt}$ & Complete & None & 1 & FCD (Palmini Ila) & 38 & 38 & la & 100 & -1 \\
\hline 7 & $\mathrm{Lt}$ & Partial (anteroinferior) & $\mathrm{OF} \& \mathrm{HC}$ & 1 & FCD (Palmini Ilb) & 33 & 33 & la & 100 & -2 \\
\hline 8 & $\mathrm{Lt}$ & Partial (anteroinferior) & ATL & 2 & FCD (Palmini Ic) & 25 & 25 & $\mathrm{lb}$ & $100^{*}$ & -3 \\
\hline 9 & Rt & Partial (posterosuperior) & Parietal operc & 1 & FCD & 12 & 0.25 & IV & $<50$ & -2 \\
\hline 10 & Rt & Partial (superior) & $\begin{array}{l}\text { Frontal operc, } \\
\text { parietal }\end{array}$ & 1 & $\begin{array}{l}\text { Rasmussen's } \\
\text { encephalitis }\end{array}$ & 48 & 3 & IIlb & $<50$ & +1 \\
\hline 11 & Rt & Partial (posterior) & ATL & 1 & TSC & 36 & 36 & la & 100 & -1 \\
\hline 12 & Rt & Partial (posterior) & $\begin{array}{l}\text { Parietal \& temporal } \\
\text { operc }\end{array}$ & 1 & $\begin{array}{l}\text { FCD ILAE Type } \\
2 a\end{array}$ & 6 & 6 & $\begin{array}{l}\text { Seizure } \\
\text { free }\end{array}$ & 100 & 0 \\
\hline 13 & $\mathrm{Lt}$ & Partial (anteroinferior) & OF & 1 & TSC & 8 & 1 & I & 90 & +1 \\
\hline
\end{tabular}

$\mathrm{ATL}=$ anterior temporal lobe; $\mathrm{HC}=$ hippocampus; $\mathrm{ILAE}=$ International League Against Epilepsy; $\mathrm{OF}=$ orbitofrontal; operc = operculum/opercula; $\mathrm{TSC}=$ tuberous sclerosis complex.

${ }^{*}$ Auras only.

high and lead to consideration of insular depth electrode placement, which should be performed in the majority of cases of suspected insular epilepsy. ${ }^{8,20,21}$ PET and ictal SPECT may show insular hypometabolism or hyperperfusion, respectively, but are rarely diagnostic due to multifocal changes from early spread or concomitant epileptic activity. ${ }^{20,21}$ Thus, the precise localization of an epileptic focus in the perisylvian/insular area is a major challenge, especially in MRI-negative patients or in patients for whom the lesion does not extend to the insula, as observed in 7 of our patients.

The aforementioned noninvasive tests often lead to neg- ative or nonspecific results. Even in patients with a welldefined epileptogenic lesion on brain MRI (e.g., focal cortical dysplasia), noninvasive investigation rarely delineates the full extent of the epileptic zone. Invasive investigation is therefore often warranted, unless all noninvasive data are congruent to a well-defined insular lesion, in which case intraoperative ECoG is justifiable. While ictal onset was solely from the insula in 5 patients, the epileptogenic zone involved adjacent neocortex in all patients. ${ }^{28}$

\section{Safety of Operculo-Insulectomy in Children}

In our series, transient hemiparesis occurred in $15 \%$ (n
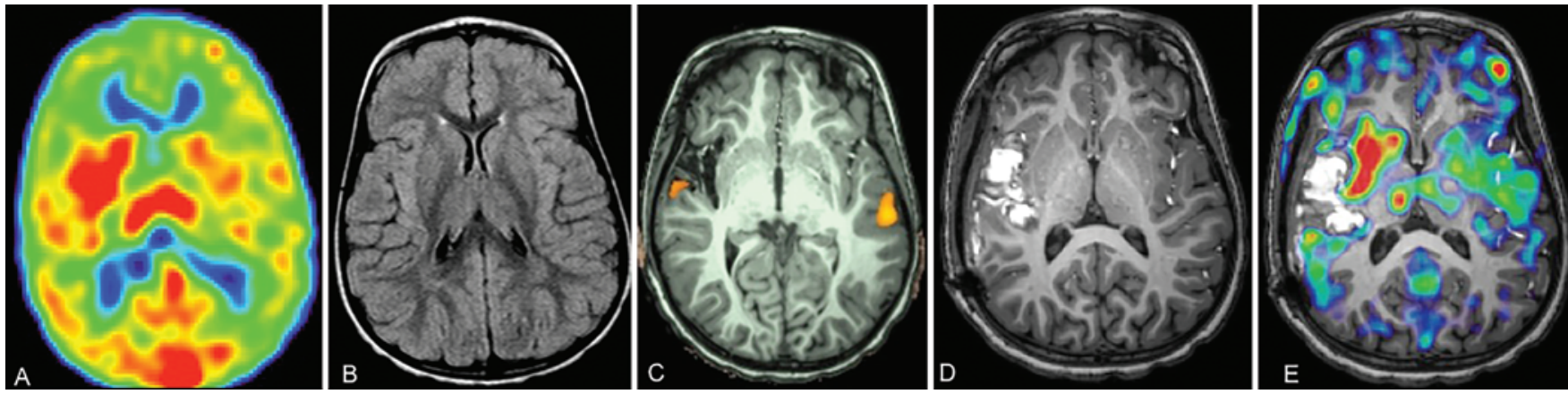

FIG. 4. Illustrative case of a failure following insulectomy. Preoperative ictal SPECT showing right temporal-opercular-insular hyperperfusion (A) and nonlesional MRI (B). Postoperative MRI (C) following right subtotal insulectomy. The patient had persistent seizures and underwent a second posterior insulectomy, as shown on postoperative MRI (D). Persistent seizures with postoperative (after the second surgery) coregistered MRI and ictal SPECT (E) showing hyperperfusion originating from the residual right anteromedial insula. Figure is available in color online only. 


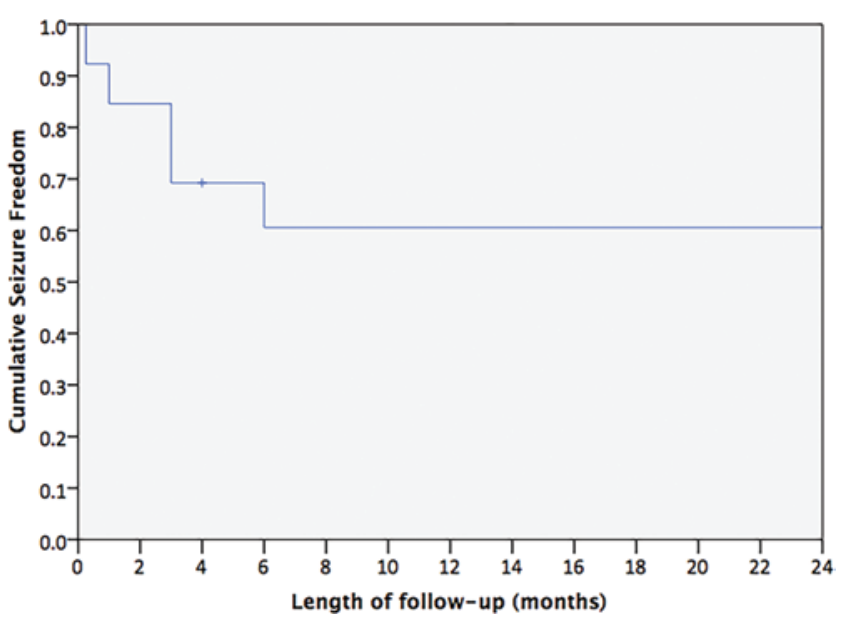

FIG. 5. Seizure freedom function in patients undergoing insular-opercular/perisylvian resection. Figure is available in color online only.

$=2$ ) of patients, which compares favorably to the literature. The rates of transient and permanent complications, such as hemiparesis and expressive aphasia, have been reported as $16 \%$ and $3 \%$, respectively, in adults undergoing insular resection for gliomas and arteriovenous malformations..$^{20,21}$ When performed for epilepsy foci in adults, most patients (57\%) develop transient hemiparesis usually as a result of unavoidable long $\mathrm{M}_{2}$ branch perforator sacrifice and subsequent corona radiata infarction; this was likely the cause of the hemiparesis in 1 of our patients. ${ }^{9} 19$ Although typically transient, permanent hemiparesis can occur in up to $20 \%$ of reported pediatric insulectomies. ${ }^{8}$ Surgical experience is likely an important factor in preventing permanent motor deficits. Careful preservation of the MCA branches and lenticulostriate vessels and restricting insular resection to the cortex without extending down into the white matter of the extreme capsule may help prevent permanent motor deficit.

Insular glioma surgery has been reported to increase the decline in learning and memory compared with resection of gliomas in other regions. ${ }^{31} \mathrm{~A}$ recent study showed that insulectomy for drug-resistant epilepsy does not result in major permanent neuropsychological impairment in the vast majority of patients.,17 Oro-motor speed and lexical access were the only affected components on neuropsychological testing. ${ }^{3}$ However, recurrent seizures in children can adversely affect the developing brain, leading to cognitive, functional, and social impairment. Insulectomy can be safely performed in children as postoperative motor deficits are almost always transient and, although impairment can occur in some neuropsychological domains, the overall outcome is likely to improve with better seizure control. The absence of neurocognitive data in our study is an important limitation in assessing safety and efficacy.

\section{Efficacy of Operculo-Insulectomy}

The $69 \%$ seizure-freedom rate in our series compares favorably to the 28 reported cases of pediatric drug-resistant, focal epilepsy surgery of the insula/perisylvian regions, in whom seizure-free outcome (Engel Class I) was obtained in most (70\%) cases..$^{5,8,11,18,24,25,30}$ However, $31 \%$ (n $=4$ ) in our series required a second procedure to complete the insulectomy and improve seizure outcome (Fig. 4). These 4 cases underwent partial insulectomy based on data obtained from the initial intracranial video-EEG. All 4 insular reoperations occurred in patients with nonlesional epilepsy (Fig. 2, Tables 3 and 4). Three of these patients $(75 \%)$ achieved seizure freedom after the second insular resection, suggesting that the entire insula is possibly involved in the primary epileptogenic zone and complete resection of the insula may be warranted for seizure freedom, particularly in nonlesional cases. Mapping the location and extent of the epileptogenic zone was challenging in these nonlesional cases, particularly in the perisylvian region, as they rely on SPECT, PET, and intracranial electrode mapping. This highlights both the difficulty in limiting the extent of resection, particularly in nonlesional cases, and the technical challenge of assessing extent of insulectomy intraoperatively. However, this rate of reoperation and the rate of seizure freedom are reflective of the published pediatric literature given that our cohort mostly comprised patients with nonlesional, extratemporal drugresistant epilepsy.

This study highlights the complexity of evaluating the extent of insular involvement in the generation of seizures and the difficulty in achieving a complete and successful single-stage resection of insular cortex. Surgical exposure of the entire extent of the insula at one time is difficult as the MCA branches drape over its surface, and the overlying opercula and superficial and deep sylvian veins restrict their exposure. Damage to these vessels risks compromising the vascular supply of the insula and the opercular cortex with subsequent ischemic injury. The poor outcome in 1 patient was likely related to the diagnosis of Rasmussen's encephalitis. Preoperatively, although there were concerns about Rasmussen's encephalitis, the absence of progressive atrophy over a 1-year period was strong evidence against it, and the patient was considered to have focal epilepsy related to perisylvian gliosis/atrophy. For this reason, and because he did not have a hemispheric syndrome (hemiplegia, homonymous hemianopia), he did not undergo hemispherectomy.

Data from this series and 2 other pediatric series confirm that isolated insular involvement is uncommon (Table 5). ${ }^{8}$ The epileptogenic zones typically include adjacent neocortex, and resection of these areas is required to achieve good seizure outcome. This agrees with other pediatric series in which the epileptogenic zone in insular cases almost always extends to adjacent cortex and reduces the likelihood of seizure freedom. ${ }^{8,30}$ In a series of adults $(n=18)$ and children $(n=6), 8$ of the 24 patients had seizures arising from the insula alone as determined by invasive EEG recordings, and $75 \%$ became seizure free. In the remaining 16 patients, seizures arose from both the insula and adjacent neocortex, and only $56 \%$ became seizure free.

Limitations of our study include the small sample size and the retrospective data review. Furthermore, the followup period was short $(<12$ months $)$ in 2 of our patients, and assessment of efficacy should be analyzed with caution. Future studies should include reevaluating surgical 


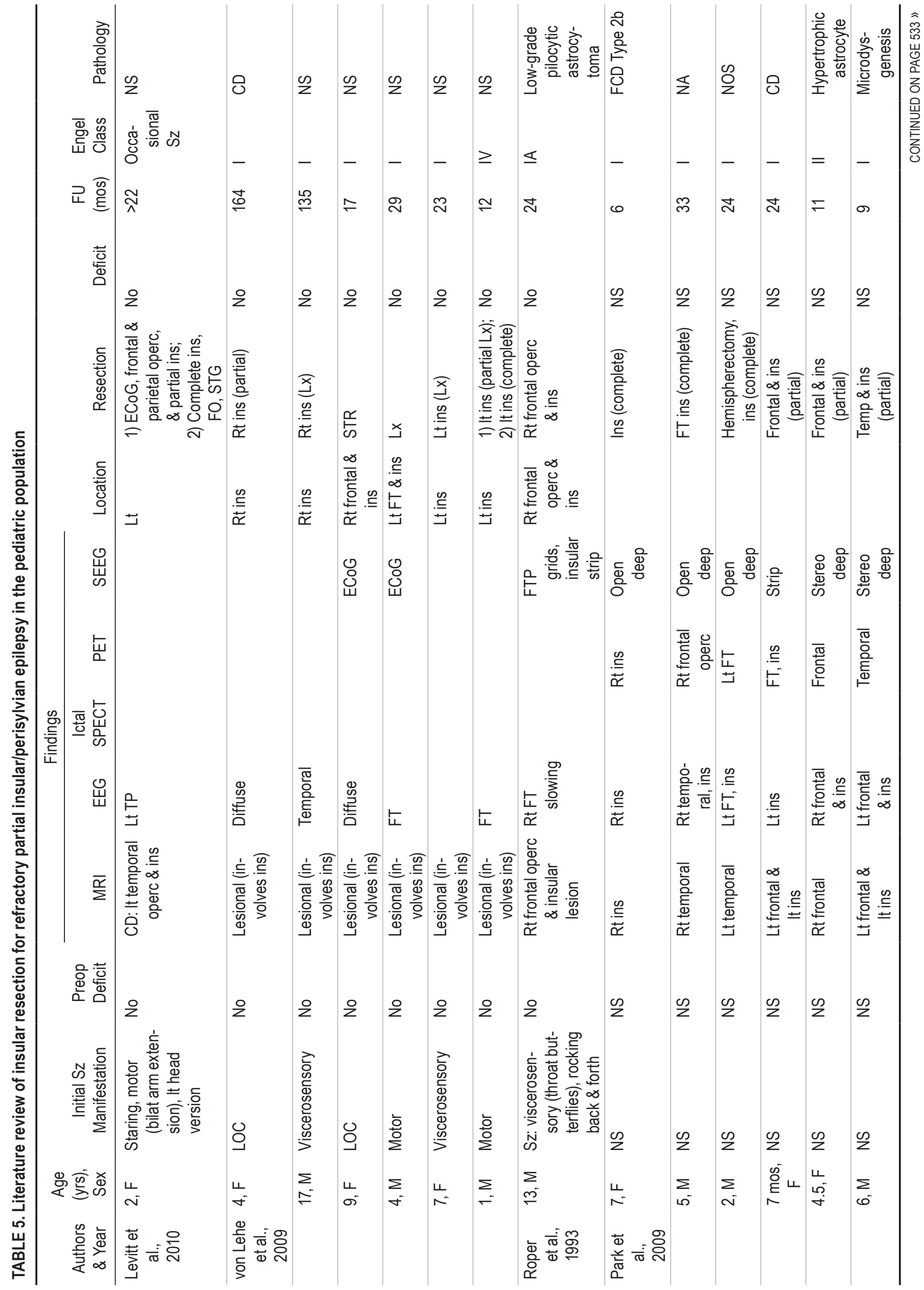




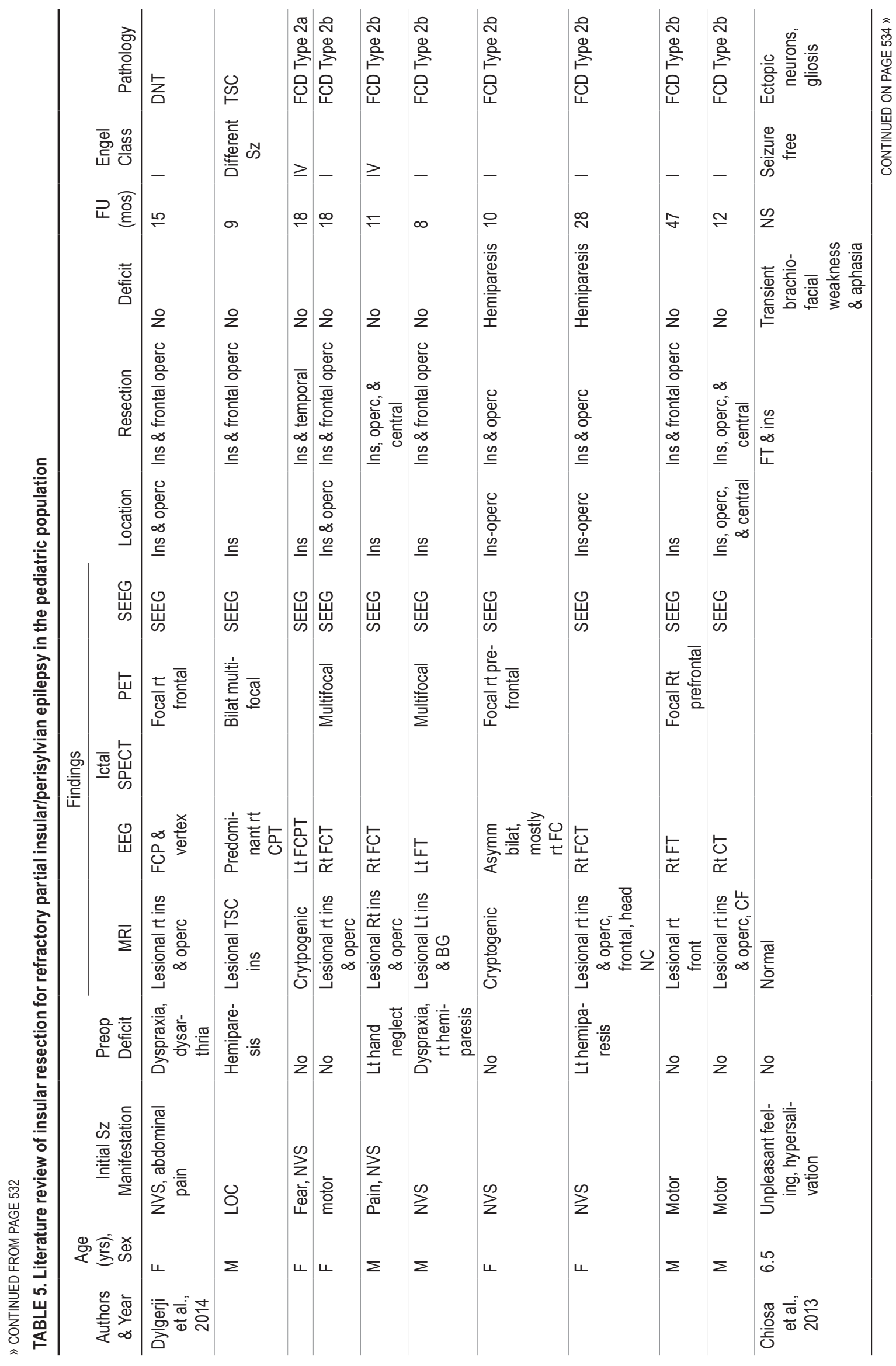




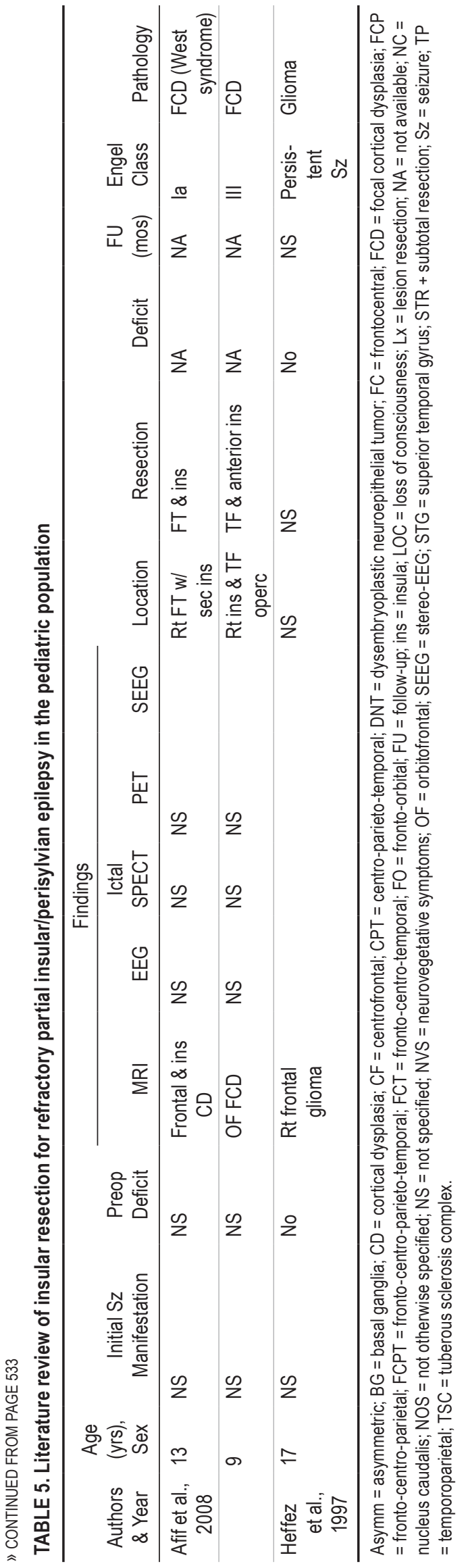

failures in patients with prior frontotemporal resections and resections involving widespread electrographic fields for evidence of insular involvement, as well as the use of stereo-EEG instead of depth electrodes.

\section{Conclusions}

Pediatric refractory insular-opercular epilepsy is complex. Surgery is safe and good outcome can be obtained in the majority of cases. Our results suggest that more radical insulectomy may be warranted in some patients to avoid reoperation and improve seizure outcome.

\section{References}

1. Afif A, Chabardes S, Minotti L, Kahane P, Hoffmann D: Safety and usefulness of insular depth electrodes implanted via an oblique approach in patients with epilepsy. Neurosurgery 62 (5 Suppl 2):ONS471-ONS480, 2008

2. Berkovic SF, McIntosh AM, Kalnins RM, Jackson GD, Fabinyi GC, Brazenor GA, et al: Preoperative MRI predicts outcome of temporal lobectomy: an actuarial analysis. Neurology 45:1358-1363, 1995

3. Boucher O, Rouleau I, Escudier F, Malenfant A, Denault C, Charbonneau S, et al: Neuropsychological performance before and after partial or complete insulectomy in patients with epilepsy. Epilepsy Behav 43:53-60, 2015

4. Burneo JG, Villanueva V, Knowlton RC, Faught RE, Kuzniecky RI: Kaplan-Meier analysis on seizure outcome after epilepsy surgery: do gender and race influence it? Seizure 17:314-319, 2008

5. Chiosa V, Granziera C, Spinelli L, Pollo C, Roulet-Perez E, Groppa S, Seeck M: Successful surgical resection in nonlesional operculo-insular epilepsy without intracranial monitoring. Epileptic Disord 15:148-157, 2013

6. Desai A, Bekelis K, Darcey TM, Roberts DW: Surgical techniques for investigating the role of the insula in epilepsy: a review. Neurosurg Focus 32(3):E6, 2012

7. Desai A, Jobst BC, Thadani VM, Bujarski KA, Gilbert K, Darcey TM, et al: Stereotactic depth electrode investigation of the insula in the evaluation of medically intractable epilepsy. J Neurosurg 114:1176-1186, 2011

8. Dylgjeri S, Taussig D, Chipaux M, Lebas A, Fohlen M, Bulteau C, et al: Insular and insulo-opercular epilepsy in childhood: an SEEG study. Seizure 23:300-308, 2014

9. Finet P, Nguyen DK, Bouthillier A: Vascular consequences of operculoinsular corticectomy for refractory epilepsy. J Neurosurg 122:1293-1298, 2015

10. Guenot M, Isnard J: [Epilepsy and insula.] Neurochirurgie 54:374-381, 2008 (Fr)

11. Heffez DS: Stereotactic transsylvian, transinsular approach for deep-seated lesions. Surg Neurol 48:113-124, 1997

12. Isnard J, Guénot M, Ostrowsky K, Sindou M, Mauguière F: The role of the insular cortex in temporal lobe epilepsy. Ann Neurol 48:614-623, 2000

13. Isnard J, Guénot M, Sindou M, Mauguière F: Clinical manifestations of insular lobe seizures: a stereo-electroencephalographic study. Epilepsia 45:1079-1090, 2004

14. Isnard J, Mauguière F: [The insula in partial epilepsy.] Rev Neurol (Paris) 161:17-26, 2005 (Fr)

15. Jayakar P, Duchowny M, Resnick TJ, Alvarez LA: Localization of seizure foci: pitfalls and caveats. J Clin Neurophysiol 8:414-431, 1991

16. Jayakar P, Gaillard WD, Tripathi M, Libenson MH, Mathern GW, Cross JH: Diagnostic test utilization in evaluation for resective epilepsy surgery in children. Epilepsia 55:507-518, 2014

17. Kan P, Van Orman C, Kestle JR: Outcomes after surgery for 
focal epilepsy in children. Childs Nerv Syst 24:587-591, 2008

18. Levitt MR, Ojemann JG, Kuratani J: Insular epilepsy masquerading as multifocal cortical epilepsy as proven by depth electrode. J Neurosurg Pediatr 5:365-367, 2010

19. Malak R, Bouthillier A, Carmant L, Cossette P, Giard N, Saint-Hilaire JM, et al: Microsurgery of epileptic foci in the insular region. J Neurosurg 110:1153-1163, 2009

20. Nguyen DK, Nguyen DB, Malak R, Bouthillier A: Insular cortex epilepsy: an overview. Can J Neurol Sci 36 (Suppl 2):S58-S62, 2009

21. Nguyen DK, Nguyen DB, Malak R, Leroux JM, Carmant L, Saint-Hilaire JM, et al: Revisiting the role of the insula in refractory partial epilepsy. Epilepsia 50:510-520, 2009

22. Oppenheimer SM, Gelb A, Girvin JP, Hachinski VC: Cardiovascular effects of human insular cortex stimulation. Neurology 42:1727-1732, 1992

23. Paolicchi JM, Jayakar P, Dean P, Yaylali I, Morrison G, Prats A, et al: Predictors of outcome in pediatric epilepsy surgery. Neurology 54:642-647, 2000

24. Park YS, Lee YH, Shim KW, Lee YJ, Kim HD, Lee JS, et al: Insular epilepsy surgery under neuronavigation guidance using depth electrode. Childs Nerv Syst 25:591-597, 2009

25. Roper SN, Lévesque MF, Sutherling WW, Engel J Jr: Surgical treatment of partial epilepsy arising from the insular cortex. Report of two cases. J Neurosurg 79:266-299, 1993

26. Ryvlin P, Kahane P: The hidden causes of surgery-resistant temporal lobe epilepsy: extratemporal or temporal plus? Curr Opin Neurol 18:125-127, 2005

27. Ryvlin P, Minotti L, Demarquay G, Hirsch E, Arzimanoglou A, Hoffman D, et al: Nocturnal hypermotor seizures, suggesting frontal lobe epilepsy, can originate in the insula. Epilepsia 47:755-765, 2006

28. Scholly J, Valenti Hirsch MP, Bartolomei F, Seegmuller AC, Boulay C, De Saint-Martin A, et al: Auditory-verbal reminiscence experiences suggesting a functional interaction of insular-temporal networks: Cortical stimulation data in epileptic patients. Epilepsia 55 (Suppl 2):22, 2014 (Abstract \#053)

29. Surbeck W, Bouthillier A, Weil AG, Crevier L, Carmant L, Lortie A, et al: The combination of subdural and depth electrodes for intracranial EEG investigation of suspected insular (perisylvian) epilepsy. Epilepsia 52:458-466, 2011

30. von Lehe M, Wellmer J, Urbach H, Schramm J, Elger CE, Clusmann H: Insular lesionectomy for refractory epilepsy: management and outcome. Brain 132:1048-1056, 2009
31. Wu AS, Witgert ME, Lang FF, Xiao L, Bekele BN, Meyers CA, et al: Neurocognitive function before and after surgery for insular gliomas. J Neurosurg 115:1115-1125, 2011

\section{Disclosures}

The authors report no conflict of interest concerning the materials or methods used in this study or the findings specified in this paper.

\section{Author Contributions}

Conception and design: Bhatia, Weil, Le, Duchowny. Acquisition of data: Weil, Le. Analysis and interpretation of data: Bhatia, Weil, Le, Fallah, Duchowny. Drafting the article: Weil, Le, Fallah. Critically revising the article: Bhatia, Weil, Le, Jayakar, Miller, Fallah, Duchowny. Reviewed submitted version of manuscript: all authors. Statistical analysis: Fallah. Study supervision: Bhatia, Jayakar, Resnick, Duchowny.

\section{Supplemental Information} Companion Papers

Weil AG, Fallah A, Lewis EC, Bhatia S: Medically resistant pediatric insular-opercular/perisylvian epilepsy. Part 1: invasive monitoring using the parasagittal transinsular apex depth electrode. DOI: 10.3171/2016.4.PEDS15636.

\section{Previous Presentations}

The preliminary data were presented at the American Epilepsy Society Annual Meeting in December 2013.

\section{Current Affiliations}

Dr. Weil: Sainte Justine Hospital, University of Montreal, Canada.

Dr. Fallah: Department of Neurosurgery, David Geffen School of Medicine at the University of California, Los Angeles, CA.

\section{Correspondence}

Sanjiv Bhatia, Department of Neurosurgery, Nicklaus Children's Hospital, 3100 Ambulatory Care Bldg., SW 62nd Ave., Miami, FL 33155. email: sanjiv.bhatia@mch.com. 